\title{
A FICÇÃO LITERÁRIA COMO ANTROPOLOGIA ESPECULATIVA
}

\section{LITERARY FICTION AS SPECULATIVE ANTHROPOLOGY}

Maria Rosa Duarte de Oliveira*

RESUMO: A partir dos pressupostos teóricos sobre a natureza do ficcional à luz de pensadores diversos como Wolfgang Iser, Huizinga, Zumthor e Juan José Saer, procuraremos refletir sobre o ficcional-literário a partir de seus fundamentos antropológicos, seja a plasticidade e o jogo (Iser, Huizinga), seja a voz (Zumthor) ou a especulação entre realidade-irrealidade (Saer), para, num segundo momento, podermos confrontar esses pressupostos teóricos com a configuração do efeito estético em duas narrativas de dois dos maiores escritores brasileiros: Machado de Assis e Guimarães Rosa.

ABSTRACT: Based on theoretical speculations on the nature of fiction, with reference to various thinkers such as Wolfgang Iser, Huizinga, Zumthor and Juan José Saer, this paper will reflect about the fictional-literary beginning with its anthropological foundations, be it the plasticity and the game (Iser, Huizinga), the voice (Zumthor) or the speculation between reality-unreality (Saer), in order to afterwards confront these theoretical conjectures with the configuration of the aesthetic effect in two narratives from two of the greatest Brazilian writers: Machado de Assis and Guimarães Rosa.

PALAVRAS-CHAVE: ficção; imaginário; realidade; efeito estético; antropologia especulativa.

KEY-WORDS: fiction; imaginary; reality; aesthetic effect; speculative anthropology.

\footnotetext{
* Professora doutora e titular em Teoria Literária e Literatura Brasileira do Programa de Pós-Graduação em Literatura e Crítica Literária da PUCSP. mrduarte@uol.com.br
} 
Não se escrevem ficções para esquivar-se, por imaturidade ou irresponsabilidade, do rigor que exige o tratamento da "verdade", senão justamente para por em evidência o caráter complexo da situação, caráter complexo para o qual o tratamento limitado ao verificável implica uma redução abusiva e um empobrecimento.

Ao dar um salto para o inverificável, a ficção multiplica ao infinito as possibilidades de tratamento [...] A ficção não é, portanto, uma reivindicação do falso. Ainda aquelas ficções que incorporam o falso de um modo deliberado - fontes falsas, atribuições falsas, confusão de dados históricos com imaginários, etc-, fazem-no não para confundir o leitor, mas para assinalar o caráter duplo da ficção, que mistura, de maneira inevitável, o empírico com o imaginado. [...] O paradoxo próprio da ficção

reside em que se ela recorre ao falso, o faz para aumentar sua credibilidade. [...] É por terem se colocado à margem do verificável que Cervantes, Sterne, Flaubert ou Kafka nos parecem dignos de crédito. Devido a esse aspecto singular do relato ficcional, podemos definir de um modo global a ficção como uma antropologia especulativa.

(JUAN JOSE SAER)

É nos domínios do jogo sagrado que a criança, o poeta e o selvagem encontram um elemento comum.

(HUIZINGA)

Se a literatura institui uma transação ímpar com a realidade a ponto de Saer (2004) vinculá-la a uma espécie de antropologia especulativa sobre a zona de fronteira ficção-realidade, então cabe a pergunta sobre o sentido dessa possível antropologia especulativa que fascina e alimenta a imaginação dos homens desde a sua origem. Por que especulativa? Especulação sobre o quê? E mais ainda: qual a função de tal atividade especulativa para a existência humana?

Iser (1996) corrobora com essa idéia ao enfatizar que o ficcional e o imaginário fazem parte das disposições antropológicas da humanidade e, por isso, estão presentes também na vida real, não se restringindo apenas à literatura. Mas é aqui que elas atingem um caráter especulativo sobre a 
existência ao colocar em questionamento a zona intervalar que separa a realidade da irrealidade, confrontando as frágeis certezas de uma lógica bipolar e não-contraditória.

Toda a questão está, pois, em considerar a ficção num campo relacional ternário com seus dois outros constituintes: a realidade, com suas determinações de espaço-tempo, e a irrealidade livre do imaginário. Ao se emancipar da polaridade com o seu outro - o mundo real - a ficção ganha estatuto próprio de um universo que tem opacidade e matéria, constituindo-se por coordenadas singulares de espaço-tempo e habitada por seres cuja carnalidade se faz por meio da performance da imaginação, entendida como pensamento plasmador de formas cuja existência se torna vívida na experiência sensório-cognitiva do leitor, em resposta ao pacto de ficção firmado com um mundo no qual habita pelo tempo que durar o seu sequestro voluntário.

A ficção, do ponto de vista de Iser, implica, desse modo, duas transgressões simultaneamente: a primeira ao "irrealizar o real", não reproduzindo o universo empírico, mas transformando-o em signo de algo diferente dele mesmo, por meio do imaginário - livre e aberto às invenções de novas ordens. A segunda transgressão, no entanto, consiste em "realizar o irreal", isto é, em passar desse nível de irrealidade do imaginário, no qual tudo é possível acontecer, para o de "tornar real" um universo ficcional cuja existência e singularidade se fazem por meio de leis e determinações próprias.

Quando a realidade repetida no fingir se transforma em signo, ocorre forçosamente uma transgressão de sua determinação correspondente. $\mathrm{O}$ ato de fingir é, portanto, uma transgressão de limites. Nisso se expressa a sua aliança com o imaginário. Contudo o imaginário é por nós experimentado antes de modo difuso, informe, fluido e sem um objeto de referência [...] Por isso o fingir tampouco é idêntico ao imaginário. Como o fingir se relaciona com o estabelecimento de um objetivo, devem ser mantidas representações de fins, que então constituem a condição para que o imaginário seja transladado a uma determinada configuração, que se diferencia dos fantasmas, projeções, sonhos e ideações sem um fim, pelas quais o imaginário penetra diretamente em nossa experiência. Portanto também aqui se verifica uma transgressão de limites, que conduz do difuso ao determinado [...]. É significativo que ambas as formas de transgressão de limites, realizadas pelo fingir no espaço da relação triádica, sejam de naturezas distintas. $\mathrm{Na}$ conversão da realidade vivencial repetida em signo de outra coisa, a transgressão de limites manifesta-se como uma forma de irrealização; na conversão do imaginário, que perde seu caráter difuso em favor de uma determinação, sucede uma realização do imaginário. (1983: 386-387) 
Daí que a determinação, mesmo que mínima, é condição do caráter de realidade para o imaginário, de modo que possa ganhar a configuração de um fato ficcional, agora não mais produto de um imaginário difuso, mas de uma lógica imaginativa ${ }^{1}$ capaz de projetar um mundo verossímil e consistente tornado presença viva por meio do ato imaginativo da leitura. Essa concepção da imaginação como criadora de espaços dotados de opacidade material acaba se aproximando daquilo que Zumthor diz sobre ela:

A imaginação, contrariamente ao ditado, não é louca; simplesmente ela dêsrazoa. Em vez de deduzir, do objeto com o qual se confronta, possíveis conseqüências, ela o faz trabalhar [...]. A imaginação faz funcionar no nosso espaço lúdico o objeto que capturou. (2007: 106)

Eis aí outra forma de dizer o que Iser concebera sobre o segundo movimento tansgressor da ficção: aquele que confere realidade à irrealidade do imaginário, por meio de uma lógica imaginativa e não-dedutiva que extrai da plasticidade lúdica das formas, em contínuos movimentos de aproximações e distâncias, semelhanças e dessemelhanças, o corpo nômade de um organismo vivo e dinâmico, entre o visível e o invisível.

O autor, embora apoiado sobre a recepção e os efeitos, afetivos inclusive, do texto ficcional sobre o leitor, diz algo que se aproxima disso ao afirmar que: "a representação do sujeito enche de vida o mundo do texto e assim realiza o contato com um mundo irreal.” (1983: 406)

É esse pacto ficcional a força fertilizadora da "fé poética" de que nos fala Coleridge Essa é, segundo Iser, a pragmática do imaginário que visa à fixação de um sentido feito acontecimento e experiência vívida por meio dessa operação de tradução, ou de "realização da irrealidade imaginária", por meio do ato de leitura.

Saer, por sua vez, numa linha de raciocínio próxima à de Iser, confirma, também, a relação não opositiva entre ficção e realidade e, em seu lugar, investe na complexidade desse universo cuja raiz está em tornar visível o "caminho do meio", isto é, a tênue e tensa fronteira entre a existência e a não-existência, a realidade e a irrealidade, o visível e o invisível, de modo a questionar o que chamamos de "realidade", segundo os estreitos limites da razão dedutiva.

\footnotetext{
${ }^{1}$ Esse é o termo que usa Paul Valèry em "Introdução ao método de Leonardo da Vinci" para se referir ao método de raciocínio que opera por saltos abdutivos geradores da invenção de novas formas artísticas, como é o caso de Leonardo da Vinci.
} 
Nas grandes ficções de nosso tempo, e talvez de todos os tempos, está presente esse entrecruzamento crítico entre a verdade e a falsidade, essa tensão íntima e decisiva, não isenta nem de comicidade nem de gravidade, como a ordem central de todas elas, às vezes enquanto tema explícito e às vezes como fundamento implícito de sua estrutura. O fim da ficção não é evadir-se desse conflito, mas fazer dele sua matéria, modelando-a à sua maneira'. (SAER, 2004:15)

Aí está o coração especulativo do universo ficcional que leva Saer a lançar a hipótese de ser essa, justamente, a função da literatura, ou seja, a de se constituir como uma antropologia especulativa. Mais uma vez, a reflexão de Iser se une a essa instigante concepção, ao focar na experiência da plasticidade humana a fonte antropológica e especulativa, se pudermos associar ao que diz Saer, do literário e do ficcional.

É no caráter de jogo que tal plasticidade se materializaria na experiência perceptiva do homem, segundo Iser, por meio da tensão entre o ficcional e o imaginário que se mantêm na alternância entre o ir e vir do jogo livre do ficcional, na sua transgressão não excludente da referência da realidade, e do jogo instrumental do universo da imaginação, cuja meta é realizar o irrealizável projetado. Esse é o jogo configurador do estético que se estrutura nesse vai e vem inconcluso e renovável a cada repetição, deixando como marca de seu construto uma espécie de intervalo vazio.

Neste caso, a interação do fictício e do imaginário será entendida como signo de uma disposição antropológica [...]

A transgressão de limites privilegia o jogo livre, enquanto a imaginabilidade de condições constitutivas antes possibilita um jogo instrumental [...] A interação de fictício e imaginário só se transforma em jogo se o jogo livre e o jogo instrumental se desdobram em uma inter-relação, ou, em suma, se um joga contra o outro e com ele. [...]

Tal jogo oferece então a condição constitutiva para o estético que, discursivamente, só pode ser descrito como um intervalo vazio. Se o vaivém relaciona o fictício como jogo livre a um fundamento, e se o imaginário faz com que o que é transgredido se decomponha para que as motivações possam ser concebidas, isso faz com que o jogo se realize igualmente como ganho e esquiva dos ganhos. (ISER, 1996: 274-275, grifos nossos)

É no jogo, também, entre texto e leitor que está o fundamento do ato de leitura para Iser, tendo nos vazios e na indeterminação as suas regras de controle do aleatório. Nesse sentido, há uma assimetria fundamental entre 
texto e leitor, determinando um campo de forças no qual sujeito e objeto do ato perceptivo-cognitivo estão em contínua troca de posições, num vai-evem desprovido de meta final. Configura-se aí, portanto, o que Iser chamou de experiência da "plasticidade" humana, que está na raiz do estético:

Como o jogo do texto é sempre mais do que mera exibição daquilo que o leitor espera em virtude da atração exercida pela inacessibilidade desse "mundo especular", isso faz com que este jogo possa ser jogado apenas individualmente pelo leitor. Enquanto o texto joga a mudança do que foi introduzido no jogo, o leitor pode jogar com essa transformação somente à medida que um resultado é possível. Pois a mudança parece implicar uma meta, a qual, uma vez realizada na leitura, não é propriamente confirmada pelo texto. (1996: 329)

Huizinga, por sua vez, no seu clássico Homo Ludens (1938), acaba confirmando essa raiz antropológica da ficção na atividade do jogo, que acompanha a história da humanidade desde os primórdios. No jogo, seja ele de que espécie for, encerra-se um significado que ultrapassa a mera atividade física e os estímulos sensoriais. O que há de comum é sua qualidade lúdica de prazer e de divertimento, de não-obrigatoriedade e de suspensão momentânea do tempo-espaço real por outro: o do próprio jogo, cujas regras só fazem sentido dentro dele mesmo.

No que diz respeito às características formais do jogo, todos os observadores dão grande ênfase ao fato de ser ele desinteressado. Visto que não pertence à vida "comum", ele se situa fora do mecanismo de satisfação imediata das necessidades e dos desejos e, pelo contrário, interrompe este mecanismo. Ele se insinua como atividade temporária, que tem uma finalidade autônoma e se realiza tendo em vista uma satisfação que consiste nessa própria realização. É pelo menos assim que, em primeira instância, ele se nos apresenta: como um intervalo em nossa vida quotidiana. (HUIZINGA, 2001:12-13)

Com o valor defunção cultural, o jogo encerra importantes aspectos necessários à vida das sociedades humanas, segundo Huizinga, distinguindo-se do cotidiano por implicar outro tempo-espaço que se estrutura com base num intervalo de tempo, cuja duração se faz por meio da repetição e da memória, e na delimitação de um campo sujeito a um conjunto de regras determinantes de uma ordem interna. Afora isso, a abertura para o imaginário e o compromisso voluntário e intenso da presença plena dos jogadores, que fazem do jogo o espaço de sua vida nesse momento de encontro feliz, aproximam-no dos fundamentos do estético: 
Mesmo depois de o jogo ter chegado ao fim, ele permanece como uma criação nova do espírito, um tesouro a ser conservado pela memória. É transmitido, torna-se tradição. Pode ser repetido a qualquer momento, quer seja "jogo infantil” ou jogo de xadrez, ou em períodos determinados, como um mistério. [...]

É talvez devido a esta afinidade profunda entre a ordem e o jogo que este, como assinalamos de passagem, parece estar em tão larga medida ligado ao domínio da estética. Há nele uma tendência para ser belo. Talvez este fator estético seja idêntico àquele impulso de criar formas ordenadas que penetram o jogo em todos os seus aspectos. As palavras que empregamos para designar seus elementos pertencem quase todas à estética. São as mesmas palavras com as quais procuramos descrever os efeitos da beleza: tensão, equilíbrio, compensação, contraste, variação, solução, união e desunião. O jogo lança sobre nós um feitiço: é "fascinante", "cativante". Está cheio das duas qualidades mais nobres que somos capazes de ver nas coisas: o ritmo e a harmonia. (HUIZINGA, 2001: 13)

Há ainda a considerar outros dois aspectos de afinidade entre o jogo e o estético ressaltados por Huizinga e que são fundamentais para o nosso estudo: a tensão entre ordem e acaso e a capacidade de representação. Com efeito, se há, no jogo e na ficção, a presença de regras e princípios organizadores que tornam esse mundo verossímil e corporalmente existente (é a segunda transgressão à qual se refere Iser, que transforma a irrealidade livre do imaginário em realidade no processo ternário do ficcional), há também neles a incorporação do acaso numa simbiose tensa e dialógica entre a determinação e a indeterminação; a limitação de regras ordenadoras e a liberdade e espontaneidade do acaso. Da mesma forma, o jogo e o estético são formas de representação e de simulação da experiência primordial de "ser outro" por meio da imaginação, isto é, a capacidade de criar por meio da ação imaginativa um corpo presencial e vivo.

É neste ponto que a Iser (1996), Huizinga (2001) e Saer (2004), cada um deles colocando a experiência estética nas raízes antropológicas do próprio homem - seja a da plasticidade, a do jogo ou a da especulação da fronteira entre realidade-irrealidade-, vem se juntar Zumthor (2007), que traz para esse cenário a presença da voz humana.

Zumthor conceberá o poético como manifestação de linguagem que transborda o estreito limite da letra, ao qual o termo "literatura" se vincula tradicionalmente, para implicar toda manifestação que faça da voz viva em performance o espaço criador de poesia, isto é, de um corpo vivo e 
multisensorial, capaz de resgatar o homem da efemeridade de um tempo cotidiano e pragmático. Fundado sobre as estruturas antropológicas mais profundas, o poético (e, por extensão, o literário) se manifesta desde as origens da história humana, inscrito nos cantos e danças rituais, nas fórmulas de magia e nas narrativas míticas, que hoje ressoam na performance dos cantadores de cordel, na contação de histórias em espaços de livrarias e de apresentações teatrais e até mesmo nos mais sofisticados espetáculos multimídia de poesia.

Hoje eu tenderia a explicar o conjunto de caracteres poéticos pela relação com a percepção e apreensão do tempo. A linguagem em sua função comunicativa e representativa insere-se no tempo biológico, que ela manifesta e assume, sendo assumida por ele, e sem ter sobre ele algum poder, incapaz de o abolir, e em contraparte, destinada a dissipar-se nele. A prática poética se situa no prolongamento de um esforço primordial para emanciparalinguagem (então, virtualmente, o sujeito e suas emoções, suas imaginações, comportamentos) desse tempo biológico. (ZUMTHOR, 2007: 48, grifos nossos)

Cumpre estabelecer que, para Zumthor, a voz poética, seja ou não mediada pela escrita e outros aparatos tecnológicos, tem a singularidade da duração e da corporeidade na medida em que é aquilo que enuncia no aqui e agora de sua presença. A essa dimensão performativa da palavra, que ganha uma dimensão não apenas linguística, mas vocal - o tom, o peso, o ritmo daquilo que é dito -, acrescenta-se a gestualidade expressiva do corpo do intérprete em interação com outras presenças vivas, isto é, o ambiente (espaço-tempo) no qual se insere e o público participante. Nesse conjunto multisensorial, está aquilo que Zumthor chama de performance, atributo essencial da experiência estética e única capaz de resgatar, mesmo na escrita, a presença dessa voz ancestral das origens.

$\mathrm{Na}$ escrita poética, que Zumthor chama de caligráfica ${ }^{2}$ e que corresponde, de certa forma, à escritura barthesiana como "encenação da língua", o texto transborda dos estritos limites do enunciado linguístico para se tornar

\footnotetext{
${ }^{2}$ Assim se refere Zumthor à escrita caligráfica e à sua singularidade poético-performática: "O que é com efeito caligrafar? É recriar um objeto de forma que o olho não somente leia mas olhe; é encontrar, na visão de leitura, o olhar e as sensações múltiplas que se ligam a seu exercício. Na medida em que a poesia tende a colocar em destaque o significante, a manter sobre ele uma atenção contínua, a caligrafia lhe restituiu, no seio das tradições escritas, aquilo com que restaurar uma presença perdida". (2007: 73)
} 
obra por meio da performance da leitura silenciosa, isto é, aquela que implica o corpo daquele que lê e é afetado física, sensorial, emocional e intelectualmente pela presença de um outro corpo - o do texto poético - e a ele responde por meio da imaginação criadora.

A leitura 'literária' não cessa de trapacear a leitura. Ao ato de ler integra-se um desejo de restabelecer a unidade da performance, essa unidade perdida para nós, de restituir a plenitude - por um exercício pessoal, a postura, o ritmo respiratório - pela imaginação. Esse esforço espontâneo, em vista da reconstituição da unidade, é inseparável da procura do prazer. (ZUMTHOR, 2007: 67)

\section{FACETAS DE UMA ANTROPOLOGIA ESPECULATIVA: ENTRE SANTOS DE MACHADO DE ASSIS E O RECADO DO MORRO DE GUIMARÃES ROSA}

Chegados aqui, propomo-nos a encenar em dois pequenos atos o que poderia ser essa antropologia especulativa por meio de uma leitura interpretativa instigada por tantos pensadores que primaram por assentar o literário sobre uma raiz antropológica comum.

\section{ATO 1: SOB O SIGNO DO FANTÁSTICO}

Pensar no conto machadiano Entre Santos (Gazeta de Notícias, 1886; Várias Histórias, 1895), é vê-lo, em princípio, sob a chave do fantástico por preencher, segundo Todorov, as três condições básicas do modelo de fantástico do século XIX:

1. A partir de um fato extraordinário presenciado pelo narrador-personagem (um capelão) no passado - a conversa entre santos que descem do altar e, como homens, passam a analisar os fiéis - instala-se para ele a hesitação entre a explicação natural e a sobrenatural para o fenômeno:

Não posso descrever o que senti. Durante algum tempo, que não chego a calcular, fiquei sem ir para diante nem para trás, arrepiado e trêmulo. Com certeza, andei beirando o abismo da loucura, e não caí nele por misericórdia divina (Entre Santos, 1998: 309) ${ }^{3}$

\footnotetext{
${ }^{3}$ Todas as citações do conto Entre Santos referem-se ao volume II da edição da Companhia das Letras de 1998, antologia organizada por John Gledson. A partir daqui, as referências
} 
2. Tal hesitação atinge, também, o leitor que vai sendo envolvido, da mesma forma que o capelão-narrador, pela atmosfera de mistério e de estranheza. Concorre para isso a presença de uma luz inexplicável

que não vinha de parte nenhuma, porque os lustres e castiçais estavam todos apagados [...] A luz, sem ser muito intensa, era-o demais para ladrões; além disso notei que era fixa e igual, não andava de um lado para outro, como seria a das velas ou lanternas de pessoas que estivessem roubando. (ES: 308-310)

3. Finalmente, atendendo à terceira condição do fantástico todoroviano, a representação da hesitação se faz no plano da história, a partir de um acontecimento extraordinário impulsionador desse estado de dúvida no narrador-personagem e no leitor, não derivando nem para uma leitura poética, nem para uma alegórica.

Compreendi, no fim de alguns instantes, que eles inventariavam e comentavam as orações e implorações daquele dia. Cada um notava alguma coisa. Todos eles terríveis psicólogos, tinham penetrado a alma e a vida dos fiéis, e desfibravam os sentimentos de cada um, como os anatomistas escalpelam um cadáver. (ES: 310$)$

O surpreendente, agora, está na inversão de posições: ao invés da fé, os santos, posicionando-se do ponto de vista terreno, mas sem perder o privilégio da onisciência que possuem, assumem a observação e a análise de verdadeiros realistas capazes de penetrar nas camadas mais ocultas da consciência dos homens, vendo-os para além da aparência.

O narrador-capelão, por sua vez, passa a ser, simultaneamente, o analisado do passado -"lembrou-me que eles, que vêem tudo o que se passa no interior da gente, como se fôssemos de vidro, pensamentos recônditos, intenções torcidas, ódios secretos, bem podiam ter me lido já algum pecado ou gérmen de pecado" (ES, 1998:312) e o analista do presente, que seleciona o que e como narrar, posicionando-se, agora, na posição de avaliador e anatomista do comportamento dos próprios santos: "A narração do santo foi tão longa e miúda, a análise tão complicada, que não as ponho aqui integralmente, mas em substância." (ES: 313-314, grifos nossos)

ao conto serão feitas pela sigla ES, seguida do número da página. 
Esse diálogo entre os santos acaba remetendo para dois outros: o Diálogo dos Mortos de Luciano de Samósata e o que faz alusão ao diálogo entre os deuses no canto I da Ilíada de Homero, porém, em nova chave - a do sério-cômico - herança da linhagem luciânica que acaba contaminando de mordaz ironia o discurso do narrador-personagem: "E os outros santos riram efetivamente, não daquele grande riso decomposto dos deuses de Homero quando viram o coxo Vulcano servir à mesa, mas de um riso modesto, tranqüilo, beato e católico". (ES: 316)

Neste instante, o fantástico cede lugar a outra matriz - a realista - que acaba contaminando com o tom da observação e da análise crítica toda a cena narrativa - desde os santos-personagens até o próprio narrador. Dessa forma, é do interior do próprio conto que emerge o método especulativo machadiano que acaba pondo em questão os limites entre o acontecimento extraordinário e o comum; o inexplicável e o inteligível; a razão e a desrazão; a ficção e a realidade.

Mas o mais interessante desse modo do fantástico é o efeito estético que acaba determinando, isto é, a especulação sobre os limites que separam a realidade da irrealidade. $\mathrm{E}$ isso nos aproxima do pensamento de Bessière ${ }^{4}$ (1974), que assim como outros estudiosos do fantástico vêem-no não como um gênero, mascomo um modo literário presente em diferentes modalidades de gêneros e de tempo-espaços históricos, com variantes de estratégias e efeitos. No entanto, segundo a autora, há no modo literário do fantástico uma constante do ponto de vista cognitivo: a de ser uma investigação sobre as formas de racionalidade, ao invés da simples polarização entre realidade - irrealidade:

Parece mais oportuno ligar o fantástico com uma investigação, conduzida por um ponto de vista racionalista, sobre as formas de racionalidade [...] O fantástico não pode ser considerado como o necessário e simples revés do racionalismo das Luzes. Fazendo isso, confunde-se anti-racionalismo e irracional, e relacionam-se os componentes de cada estética a um sistema de oposições exclusivas. Longe de estabelecer ou pretender rupturas intelectuais e artísticas, o fantástico conjuga os elementos contrapostos [...]. O fantástico não

\footnotetext{
${ }^{4}$ Trata-se do estudo fundamental sobre o fantástico realizado por Irène Bessière: Le récit fantastique: La poetique de l'incertain. Paris: Larousse, 1974. Há uma tradução do cap. 1 desse livro na revista eletrônica Fronteiraz 3, que pode ser acessada no endereço http:// www.pucsp.br/revistafronteiraz/
} 
deriva de uma simples divisão da psique entre razão e imaginação, liberação de uma e contenção da outra, mas da polivalência dos signos intelectuais e culturais $[. .$.$] o fantástico assinala a medida do real através da desmedida. O$ ceticismo que só marca a intimidade da razão e da desrazão é o ingrediente obrigatório do imaginável. (BESSIÈRE (1974), citada por CESERANI, 2006: 64-65, grifos nossos)

O final do conto, por sua vez, corrobora com esse estado de tensão permanente entre o acontecido e o imaginado, apostando no efeito da presença simultânea de duas matrizes - a fantástica e a realista - sem a anulação de uma pela outra:

Depois, não pude ouvir mais nada. Caí redondamente no chão. Quando dei por mim já era dia claro... Corri a abrir todas as portas e janelas da igreja e da sacristia, para deixar entrar o sol, inimigo dos maus sonhos. (ES: 316)

Nesse sentido, Entre Santos não deixa de ser um exercício de investigação sobre a relatividade das certezas (o estar entre do título é, aliás, mais um índice disso) num mundo onde as fronteiras entre o visível e o invisível, o exterior e o interior, a razão e a imaginação, a ciência e a fé - da religiosa à poética - estão sob a análise do ceticismo do autor, do narrador-capelão, que hoje relata o extraordinário sob ótica crítico-analítica, e dos próprios santos, divididos entre a figuração de personagens e a de narradores, porém, antes de tudo, anatomistas das contradições da natureza dos homens e dos santos, também eles divididos entre o céu e a terra.

Cabe, assim, inquirirmos se no traçado do conto podemos reconhecer aquilo que propôs Saer (2004) sobre a essência do literário, isto é, o de ser uma antropologia especulativa sobre a existência humana por meio da construção poética de um simulacro que nos coloca em confronto com uma situação-limite, onde não é mais possível decidir pela exclusão de um dos pólos: conto fantástico ou realista?

O olhar de míope machadiano, "aquele que vê o escondido das coisas", foi capaz de projetar mais longe o efeito estético de Entre Santos, que perdura, justamente, pela convivência tensa com a incerteza e o inacabamento do jogo, que se repete em variações sempre novas e surpreendentes, como observa Huizinga: "Mesmo depois de o jogo ter chegado ao fim, ele permanece como uma criação nova do espírito, um tesouro a ser conservado pela memória”.(2001:13) 


\title{
ATO 2: SOB O SIGNO DA VIAGEM
}

Falar sobre O Recado do Morro de Guimarães Rosa, uma das narrativas que compõem Corpo de Baile (1956), é trazer à tona a matriz da viagem que envolve o território do conto, desde as andanças do autor pelo sertão mineiro, especialmente o morro da Garça, até o plano do enredo - a expedição de cinco viajantes pelos gerais (Cordisburgo, gruta de Maquiné, serra Diamantina, Morro da Garça) sob a condução de um guia, Pedro Orósio ou Pê Boi - e da enunciação que se faz na fronteira entre o relato das cadernetas de campo, típicas de um narrador-viajante, até a sua presença testemunhal nos acontecimentos narrados; isso para não falar de outra viagem: a do recado-enigma, espécie de fórmula mágica emitida pelo próprio Morro da Garça e que percorre toda a narrativa por meio dos intérpretes que o vão transfigurando durante a travessia nômade de uma voz, só recolhida, ao final, pelo poema-canto do poeta popular:

\author{
Quando o Rei era menino \\ já tinha espada na mão \\ e a bandeira do Divino \\ com o signo-de-salomão. \\ Mas Deus marcou seu destino: \\ de passar por traição. \\ A viagem foi de noite \\ Por ser tempo de luar. \\ Os sete nada diziam \\ porque o Rei iam matar. \\ Mas o rei estava alegre \\ E começou a cantar... (RM: 94-96)
}

Esse sentido de viagem, ao cruzar a fronteira entre realidade-ficção, traz para primeiro plano aquilo que aponta Saer (2004) como a qualidade das grandes ficções: o fato de configurar-se como uma antropologia especulativa. E, no caso em análise, atinge planos ainda mais sutis ao colocar em questão o limite entre o que pode ser expresso e comunicado pela língua e aquilo que não pode, como é o caso da apreensão de um recado emitido pelo morro da Garça, duplo ficcional do verdadeiro Morro da Garça, situado

\footnotetext{
${ }^{5}$ Todas as citações do conto O Recado do Morro referem-se à 9a. ed. da Nova Fronteira de No Urubuquaquá no Pinhém (Corpo de Baile). A partir daqui, as referências ao conto serão feitas pela sigla RM seguida do número da página.
} 
bem ao centro de Minas Gerais, no hoje município de Morro da Garça, ponto geográfico marcante para os vaqueiros nas suas andanças pelo sertão mineiro.

É ele que, imponente, instaura-se como presença viva no relato por meio da audição de seu recado cuja voz pode ser percebida e traduzida por uma língua cifrada, entre o dizível e o indizível, e que só os que estão à margem podem ouvir e entender:

- H'hum... Que é que o morro não tem preceito de estar gritando...Avisando de coisas..."- [...] Lá - estava o Morro da Graça: solitário, escaleno e escuro, feito uma pirâmide [...] Em cada momento, espiava, de revés para o Morro da Garça, posto lá, a nordeste, testemunho. Belo como uma palavra. De uma feita o Gorgulho levou os olhos a ele, abertamente, e outra vez se benzeu, tirado o chapéu, depois expediu um esconjuro, com a mão canhota. [...]

- Que que disse? Del-rei, ô demo! Má hora, esse Morro, ásparo, só se é de satanaz, ho! Pois olhe que, vir gritar recado assim, que ninguém não pediu: é de tremer as peles... Por mim, não encomendei aviso nem quero ser favoroso... Del-rei, Del-rei, que eu cá é que não arrecebo dessas conversas, pelo similhante! Destino, quem marca é Deus, seus Apóstolos! E que toque de caixa? È festa? Só se for morte de alguém... Morte à traição, foi que ele morro disse. Com a caveira, de noite, feito História Sagrada, Del-rei, Del-rei!...(RM: 39, 42, 48, grifos nossos)

Esse recado preditivo percorre, paralelamente, a viagem da expedição ao modo de uma fórmula mágica, sem sentido para a razão, mas com força condutora daquilo que enuncia (o performativo), no caso, o destino da outra personagem nuclear - Pê-Boi - talhe de gigante, tão grande e imponente quanto o Morro da Garça, com quem tem a vida cruzada.

Especular o aquém da língua, as suas camadas de sentidos e de modulações de vozes oraculares guardadas na memória de cada palavra é o cerne da antropologia especulativa de Rosa. Tal meta se materializa na própria escrita, que rasura o papel e deixa vazar a voz, do que ainda não tem representação linguística, mas é um corpo vivo que enuncia tão só pela presença. Tal é o recado do Morro da Garça.

Para traduzir o indizível, o que há de mais adequado do que as fórmulas mágicas, os oráculos, a linguagem cifrada dos sonhos, os jogos sonoros e trocadilhescos, ou ainda os paradoxos que "existem para que ainda se possa exprimir algo para o qual não existem palavras". (ROSA, 2001 citado por LORENZ, 1991: 68) 
Todos eles são apenas facetas da língua poética, que transborda da palavra para a não-palavra e não é outra senão a do som sem som e da voz inaudível e indizível do que ainda não tem nome, mas é e está nas origens da história do universo e do homem.

É essa escrita que deseja ser voz, escrita caligráfica como diria Zumthor (2007), a própria corporificação do paradoxo colhido por este "caderno de campo" científico-poético do narrador-viajante. Nesse espaço, ouve-se/lêse o próprio Rosa, como um tesouro, na memória dessa fala-canto-poemaprosa. Escrita nômade, que guarda os caminhos da voz, não para ser lida, mas para ser ouvida, vista, sentida, tocada como uma presença que entra por todos os sentidos corporais e nos leva para dentro desse lugar criado pelo relato e no qual habitamos pelo tempo que durar o encantamento:

Pelas abas das serras, quantidades de cavernas - do teto de umas poreja, solta do tempo, a aguinha estilando salobra, minando sem fim num gotejo, que vira pedra no ar, se endurece e dependura, por toda a vida, que nem renda de torrõezinhos de amêndoa ou fios de estadal, de cera-benta, cera santa, e grossas lágrimas de espermacete; enquanto do chão sobem outras, como crescidos dentes, como que aqueles sejam goelas da terra, com boca para morder. [...]

Papagaios rouco gritam: voam em amarelo, verdes. Vez em vez, se esparrama um grupo de anús, coracóides, que piam pingos choramingas. O caracará surge, pousando perto da gente, quando menos se espera _ um gaviãoão vistoso, que gutura. (RM: 29-31)

Essa especulação alquímica de Rosa faz a poesia brotar das raízes da própria língua, dos nomes cunhados pelos habitantes locais e pela tradição popular ao invés daquela trazida por filólogos e linguistas. São nomes que são o "quem" das coisas, signos motivados, que trazem já em si a qualidade daquilo que nomeiam. Não é à toa que toda a pesquisa filológica leva Rosa, cada vez mais, para dentro da poesia autêntica: aquela que não está nem nos neologismos nem nas metáforas, mas na própria raiz da língua falada pelo povo.

Meu lema é: a linguagem e a vida são uma coisa só. Quem não fizer do idioma o espelho de sua personalidade não vive; e como a vida é uma corrente contínua, a linguagem também deve evoluir constantemente. Isto significa que, como escritor, devo me prestar contas de cada palavra e considerar cada palavra o tempo necessário até ela ser novamente vida. O idioma é a única porta para o infinito, mas infelizmente está oculto sob montanhas de cinzas. [...] 
O bem estar do homem depende do descobrimento do soro contra a varíola

e as picadas de cobra, mas também depende de que ele devolva à palavra seu sentido original. Meditando sobre a palavra, ele se descobre a si mesmo. Com isto repete o processo da criação. (ROSA citado por LORENZ, 1991: 83)

E ei-nos aqui de volta ao começo: o da ficção como antropologia especulativa.

\section{REFERÊNCIAS BIBLIOGRÁFICAS}

ASSIS, Machado de. Entre Santos. In: GLEDSON, John. Contos de Machado de Assis. v. II. São Paulo: Companhia das Letras, 1998.

BESSIÈRE, Irene. Le récit fantastique - la poetique de l'incertain. Paris, Larousse, 1974.

CESERANI, Remo. O Fantástico. Londrina: EdUEL, 2007.

HUIZINGA, Johan. Homo Ludens. 5ª ed. São Paulo, Perspectiva, 2001.

ISER, Wolfgang. O Fictício e o Imaginário. Perspectivas de uma antropologia literária. Rio de Janeiro: EdUERJ, 1996.

Os atos de fingir ou o que é fictício no texto ficcional. In: COSTA LIMA, Luiz. Teoria da Literatura em suas fontes. V. II. 2a. ed. Rio de Janeiro: Francisco Alves, 1983.

LORENZ, Günther. Diálogo com Guimarães Rosa. In: COUTINHO, Eduardo (org.). Guimarães Rosa. Coleção Fortuna Crítica. 2a . ed. Rio de Janeiro: Civilização Brasileira, 1991.

OLIVEIRA, Maria Rosa Duarte de. A viagem em Guimarães Rosa: espaços nômades entre identidade e alteridade. In: Revista Cerrados. Literatura e Presença: Guimarães Rosa. Brasília: Editora da UNB, 2008, p. 29-40.

"Entre Santos" de Machado de Assis: um conto fantástico? In: GOMES, André Luís. (org). Cenas Avulsas: ensaios sobre a obra de Machado de Assis. Brasília: LGE Editora, 2008, p.169- 182. 
ROSA. João Guimarães. O Recado do Morro. In: ___ No Urubuquaquá, no Pinhém (Corpo de Baile). 9a. ed. Rio de Janeiro: Nova Fronteira, 2001.

SAER, Juan José. El concepto de ficción. Buenos Aires: Seix Barral, 2004. __L La narración-objeto. Buenos Aires: Editorial Planeta, 1998.

ZUMTHOR, Paul. Performance, Recepção, Leitura. 2a. ed. São Paulo: Cosac Naify, 2007. 